\title{
ANALISIS KEKUATAN MEKANIK EXHAUST COVER KOMPOSIT HYBRID UNTUK SEPEDA MOTOR DENGAN METODE VACUUM INFUSION
}

\author{
Andika Wisnujati ${ }^{1}$, Ferriawan Yudhanto² \\ Program Studi D3 Teknik Mesin, Universitas Muhammadiyah Yogyakarta \\ Jl. Lingkar Selatan, Tamantirto, Kasihan, Bantul, Daerah Istimewa Yogyakarta, Indonesia \\ andikawisnujati@umy.ac.id ${ }^{1}$, ferriawanyudhanto123@yahoo.com²
}

\begin{abstract}
Abstrak
Penelitian ini membahas proses pembuatan cover knalpot sepeda motor Honda Beat dengan menggunakan komposit hybrid bahan serat alam (serat rami) dan serat sintetis (fiber glass). Metode yang digunakan dalam pembuatan produk adalah metode vacuum infusion dengan pola aliran samping. Tujuan dari penelitian ini adalah untuk membuat produk cover knalpot yang ringan dan memiliki kekuatan yang tinggi. Matriks yang digunakan adalah Unsaturated Polyester Resin (UPR) dari PT. Justus Kimia Raya. Sifat kekuatan bahan dapat diketahui dengan melakukan pengujian tarik standar ASTM D638 dan pengujian impact charpy ASTM D5942. Hasil pengujian tarik sebesar 139,46 Mpa, dan pengujian impak didapatkan nilai sebesar $0,0527 \mathrm{~J} / \mathrm{mm}^{2}$. Selain itu produk komposit hybrid yang dihasilkan lebih ringan dan sifat lebih ulet dibanding cover knalpot pada produk sepeda motor Honda Beat genuine part.
\end{abstract}

Kata kunci: Komposit, Vacuum Infusion, Serat Rami, Uji Tarik, Uji Impak.

\section{Pendahuluan}

Pemakaian logam khususnya baja sebagai bahan baku dalam dunia manufaktur dan konstruksi mulai berkurang seiring dengan perkembangan teknologi dan pertimbangan terhadap masalah lingkungan dalam pengembangan material teknik. Material komposit khususnya dengan penguatan serat alam mulai dikembangakan karena meningkatnya kebutuhan akan material yang kuat, ringan, tahan korosi, murah dan ramah lingkungan [1].

Serat alami (natural fiber) adalah serat yang berasal dari tumbuhan atau hewan yang bersulur-sulur seperti benang. Untuk mendapatkan bentuk serat, diperlukan beberapa tahap pemrosesan tergantung pada karakter bahan dasarnya. Serat dari tumbuhan antara lain kapas, pelepah pisang, enceng gondok, dan rami. Sedangkan serat dari hewan misalnya wool, sutra, dan bulu burung.

Dengan demikian subsitusi penggunaan bahan-bahan sintetis dengan bahan alami yang ramah lingkungan dan dapat diperbaharui menjadi persyaratan produk. Pemanfaatan bahan-bahan alami ini terutama serat untuk media penguatan belum banyak diaplikasikan pada bagian struktur yang mampu menerima beban dari luar khususnya untuk aplikasi-aplikasi khusus.

Penggunaan serat alam sebagai penguat pada material komposit polimer memberikan beberapa keuntungan karena serat alam memiliki massa jenis yang rendah, mampu terbiodegradasi, mudah didaur ulang, harga murah serta memiliki sifat mekanik yang baik dan dapat diperbaharui karena berasal dari alam.

Serat rami merupakan tanaman yang memiliki kandungan serat yang tinggi. Pemanfaatan serat rami di Indonesia pada saat ini hanya sebatas sebagai bahan dasar pembuatan pakaian, kertas dan alat rumah tangga yang sederhana dan murah. Tentunya akan mempunyai nilai lebih, jika serat tersebut dapat digunakan untuk menggantikan serat non alam yang selama 
ini masih diimpor dari luar negeri sebagai penguat material komposit. Bahkan pusat riset Daimler Chrysler di Eropa mengungkapkan bahwa serat alam mempunyai potensi yang kuat dalam industri automotive jika dibandingkan dengan serat gelas, karena harganya murah dan ringan.

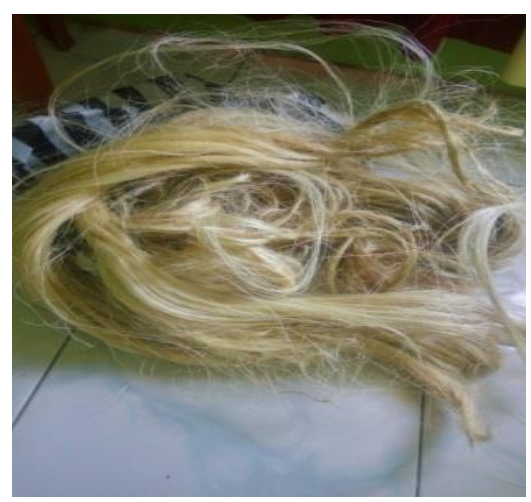

Gambar 1. Serat Rami

Biokomposit merupakan salah satu jenis komposit yang tersusun dari serat alam sebagai penguat dan matrik alam atau matrik sintetis sebagai perekat. Biokomposit yang berbahan dasar natural merupakan fenomena menarik untuk diteliti karena ramah lingkungan, sumber bahan baku yang dapat diperbaharui.

Analisa efek hybrid bertujuan untuk menentukan apakah campuran serat penguat yang dipilih dengan jenis matrik yang dipergunakan dalam pembuatan komposit hybrid. Efek hybrid bernilai positif atau negatif menggambarkan penyimpangan sifat mekanis dari kaidah campuran (Rule Of Hybrid Mixture). Jika nilai kekuatan di atas nilai Rule Of Hybrid Mixture maka efek hybrid bernilai positif. Jika nilai kekuatan dibawah nilai Rule $O f$ Hybrid Mixture maka efek hybrid bernilai negative. Penelitian ini bertujuan untuk mengetahui ketangguhan bahan komposit serat hybrid produk cover knalpot yang diperkuat serat rami.

\section{TINJAUAN TEORITIS}

Fauzan melakukan penelitian tentang analisis dansitas dan kekuatan material komposit berpenguat serat glass dari hasil metode Vacuum Infusion. Pada penelitian tersebut material komposit terdiri dari tiga lapis serat e-glass dan didapat hasil nilai rata-rata pengujian tarik sebagai berikut. Vacuum Infusion dengan aliran dari samping sebesar 179,69 Mpa dan 206,74 Mpa untuk pola aliran dari tengah serta dengan metode Press Mold menghasilkan 124,15 Mpa [2].

Lutfi melakukan penelitian analisis kekuatan tarik hybrid lamina serat anyam rami dan glass diperkuat polyester. Pada penelitian tersebut serat rami dialkalisasi menggunakan $\mathrm{NaOH} 5 \%$ selama 2 jam. Dalam pembuatan material komposit penguat yang diginakan terdiri dari 2 slapis serat alam (serat rami) dan 1 lapis serat sintetis (fiber) berpola acak dengan metode press mold. Dari hasil penelitian tersebut didapat tegangan tarik sebesar 49, $315 \mathrm{Mpa}$ dan regangan sebesar $0,602 \%$ serta modulus elastisitas sebesar 8,190 Gpa [3].

Pada produk komposit hybrid dengan metode press mold menggunaknan dua jenis serat yaitu anyaman serat gelas (woven glass fiber atau fabric) dan anyaman serat sisal hybrid kemudian dibuat dengan komposisi 3 lapisan material penguat (3-layer reinforcement). Dengan Variasi yang dilakukan 4 jenis dengan kode variasi seras sisal (S) dan Glass Fiber (FG). Variasi pertama yaitu 3 layer semua serat sisal (S-S-S), variasi kedua (FG-S-FG), variasi ketiga (S-FG-S) dan yang keempat semua serat glass (FG-FG-FG) kemudian dilakukan uji tarik dengan hasil komposit hybrid terbaik ada di hybrid 1 (FG-S-FG) sebesar $117 \mathrm{MPa}$, sedangkan pada hybrid 2 (S-FG-S) diperoleh $68 \mathrm{Mpa}$, dan yang paling rendah ada pada variasi 3 layer fabric sisal sebesar 48 Mpa [4].

Komposit adalah suatu material yang terbentuk dari kombinasi dua atau lebih material sehingga dihasilkan material komposit yang mempunyai sifat mekanik dan karakteristik yang berbeda dari material pembentuknya. Komposit terdiri dari suatu bahan utama (matrik) dan suatu jenis penguatan yang ditambahkan untuk meningkatkan kekuatan dan kekakuan 
matrik.Penguat ini biasanya dalam bentuk serat.

Komposit serat adalah komposit yang terdiri dari fiber dalam matrik. Secara alami serat yang panjang mempunyai kekuatan yang lebih dibanding serat yang berbentuk curah (bulk). Merupakan jenis komposit yang hanya terdiri dari satu lamina atau satu lapisan yang menggunakan penguat berupa serat (fiber). Serat yang digunakan bisa berupa fiber glass, carbon fibers, aramid fibers (poly aramide), dan sebagainya.

Serat ini bisa disusun secara acak maupun dengan orientasi tertentu bahkan bisa juga dalam bentuk yang lebih kompleks seperti anyaman. Serat merupakan material yang mempunyai perbandingan panjang terhadap diameter sangat tinggi.

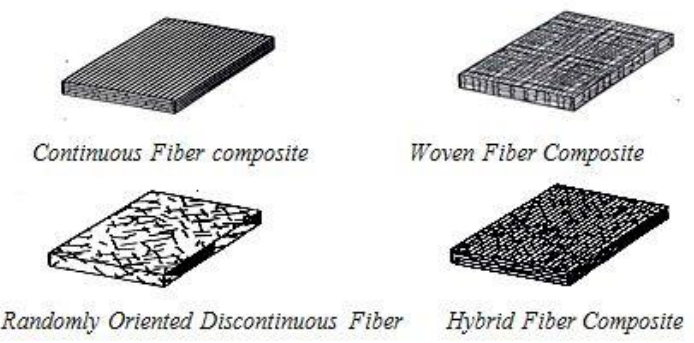

Gambar 2. Tipe serat pada komposi [6].

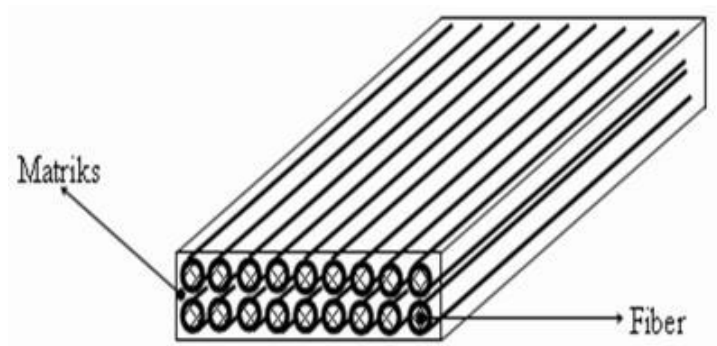

Gambar 3. Fibrous composites [6].

Komposit partikel terdiri dari matrik yang berukuran kecil dengan bentuk butir. Skema komposit partikel dapat dilihat seperti gambar 4 .

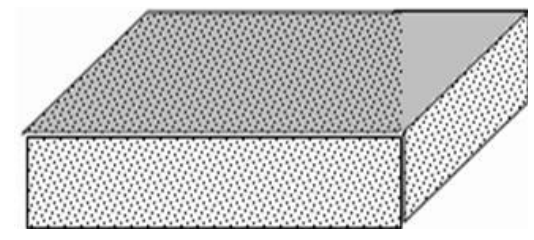

Gambar 4. Particulate composite [6].

Komposit lapis merupakan jenis komposit terdiri dari dua lapis atau lebih yang digabung menjadi satu dan setiap lapisnya memiliki karakteristik sifat sendiri.

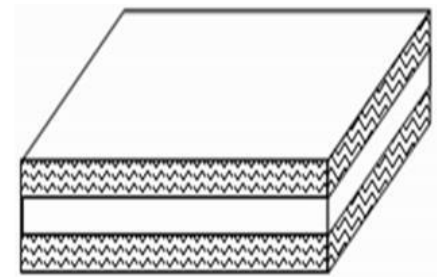

Gambar 5. Laminated composites [6].

Komposit ini terdiri dari bermacammacam lapisan material dalam satu matrik. Bentuk nyata dari komposit lamina logam adalah bimetal, komposit lamina dengan inti atau komposit sandwich.

Bahan komposit pada umumnya terdiri dari dua unsur, yaitu serat sebagai pengisi dan matriks sebagai bahan pengikat serat. Di dalam komposit unsur utamanya adalah serat, sedangkan bahan pengikatnya menggunakan bahan polimer yang mudah dibentuk dan mempunyai daya pengikat yang tinggi. Penggunaan serat sendiri diutamakan untuk menentukan karakteristik bahan komposit, seperti kekuatan, kekakuan serta sifat-sifat mekanik lainnya. Sebagai bahan pengisi, serat digunakan untuk menahan sebagian besar gaya yang bekerja pada bahan komposit

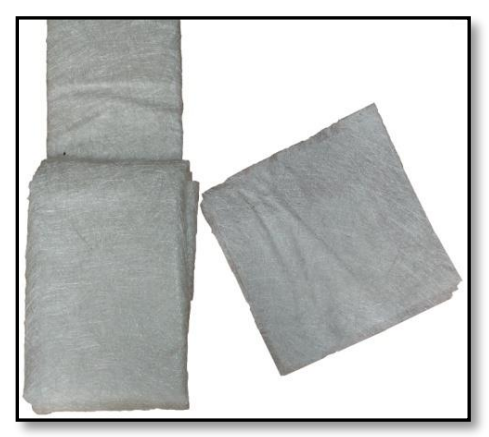

Gambar 6. Serat Glass Pola Acak

Fungsi dari Serat adalah sebagai penompang kekuatan dari komposit, sehingga tinggi rendahnya kekuatan tergantug serat yang digunakan, karena tegangan yang diterima komposit mulanya diterima oleh matrik dan diteruskan kepada serat sehingga serat akan menahan beban hingga beban maksimum. Serat glass 
mempunyai karakteristik yang berbeda antara yang satau dengan yang lain. Adanya perbedaan sifat tersebut maka dalam pengaplikasiannya dapat disesuaikan dengan sifat dan karakteristik yang dimiliki [7].

\section{METODOLOGI PENELITIAN}

Alat yang digunakan dalam proses penelitian ini meliputi Vacuum Infusion, yaitu alat untuk membuat cetakan produk dan penelitian caranya dengan memvacum udara yang masuk kedalam plastik yang di dalamnya terdapat bahan-bahan untuk membuat cetakan kemudian resin yang sudah dicampur dimasukkan dalam wadah dan akan disedot dengan selang, setelah itu maka akan masuk kedalam plastik yang disedot oleh pompa, maka resin akan mengalir dengan sendirinya.

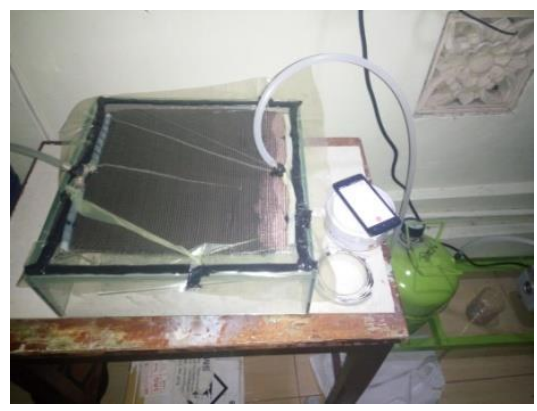

(a)

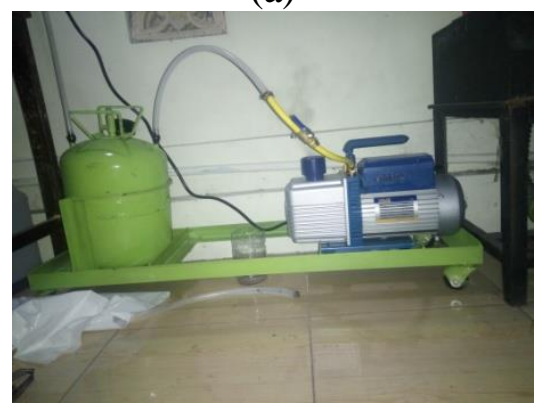

(b)

Gambar 7. (a) Plastik Cetakan Vacuum Infusion; (b) Tabung dan Alat Vacuum

Bagging Film berfungsi sebagai penutup dari seluruh sisi dari cetakan. Dalam pemakaiannya, bagging film ditempelkan pada cetakan dengan menggunakan plaster khusus (sealane tape) agar tidak terjadi kebocoran.

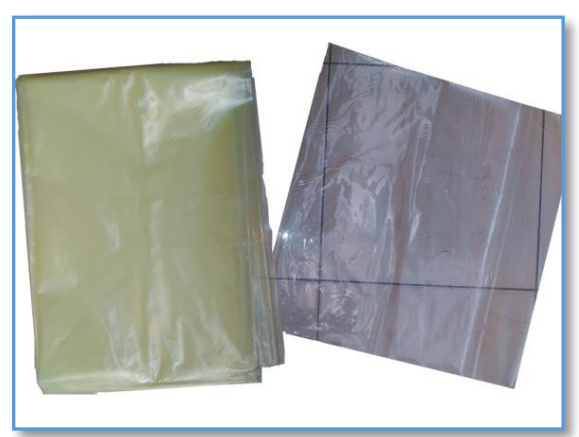

Gambar 8. Bagging Film

Flow Media Resin dapat mengaliir dengan sebagaimana mestinya jika terdapat flow media dalam catakan tersebut. Dalam kerjanya flow media meberikan celah antara serat dan bagging film, sehingga resin dapat mengalir dengan baik. Inphuply digunakan sebagi pemisah antara flow media dengan serat, dengan demikian ketika pencetak sudah selesai flow media dapat dipisahkan dari material komposit. Selain alat-alat tersebut di atas, juga terdapat alat pendukung yang lain seperti : timbangan digital; gelas ukur; gelas plastik; pipet; jangka sorong digital; gerinda; gergaji dan masker serta sarung tangan.

Jenis resin yang biasa digunakan sebagai matrik pada komposit adalah Unsaturated Polyester Resin (UPR) atau juga disebut polyester. Jenis resin tersebut tergolong resin dengan viskositas rendah yang dapat mengeras pada suhu kamar dengan menggunakan katalis. Resin jenis polyester banyak ditemukan dipasaran, salah satu jenisnya adalah Yucalac 157 BQTN-EX Series. Spesifikasi dari produk tersebut adalah sebagai berikut:

Tabel 1. Spesifikasi UPR Yucalac 157 BQTN-EX

\begin{tabular}{|c|c|c|c|}
\hline Item & Satuan & Nilai Tipikal & Keterangan \\
\hline Massa jenis & Gram/cm & 1,215 & $25^{\circ}$ \\
\hline Kekerasan & - & 40 & Borcol YGZJ 934-1 \\
\hline Suhu distorsi panas & ${ }^{\circ} \mathrm{C}$ & 70 & \\
\hline Penyerapan air & $\%$ & 1,88 & $24 \mathrm{Jam}$ \\
\hline Suhu ruang & $\%$ & 0,466 & 7 Hari \\
\hline Kekuatan Flexural & $\mathrm{kg} / \mathrm{mm}$ & 9,4 & - \\
\hline Modulus Flexural & $\mathrm{kg} / \mathrm{mm}$ & 300 & - \\
\hline Daya Rentang & $\mathrm{kg} / \mathrm{mm}$ & 5,5 & - \\
\hline Modulus Rentang & $\mathrm{kg} / \mathrm{mm}$ & 300 & - \\
\hline Elongasi & $\%$ & 2,1 & - \\
\hline
\end{tabular}

\section{Proses pembuatan panel}

1. Melakukan proses alkalisasi dengan cara merendam serat rami ke dalam 
campuran $\mathrm{NaOH} 5 \%$ (300 gram) dengan 6 liter air selama 4 jam dengan kandungan $\mathrm{NaOH}$ didalamnya sebesar $96 \%$.

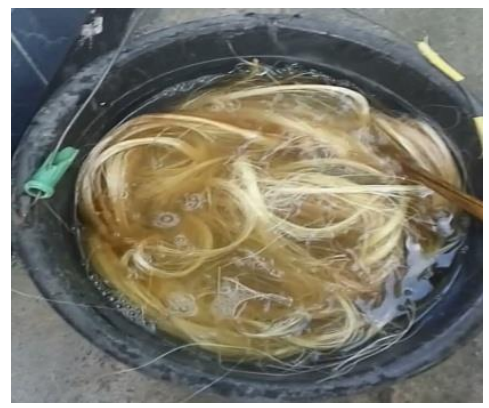

Gambar 9. Proses alkalisasi

2. Melakukan penjemuran serat rami tanpa terkena sinar matahari secara langsung.

3. Melakukan pemisahan serat pada serat rami untuk mendapatkan ukuran dan panjang yang seragam.

4. Melakukan penenunan serat untuk mendapatkan serat rami berpola anyam.

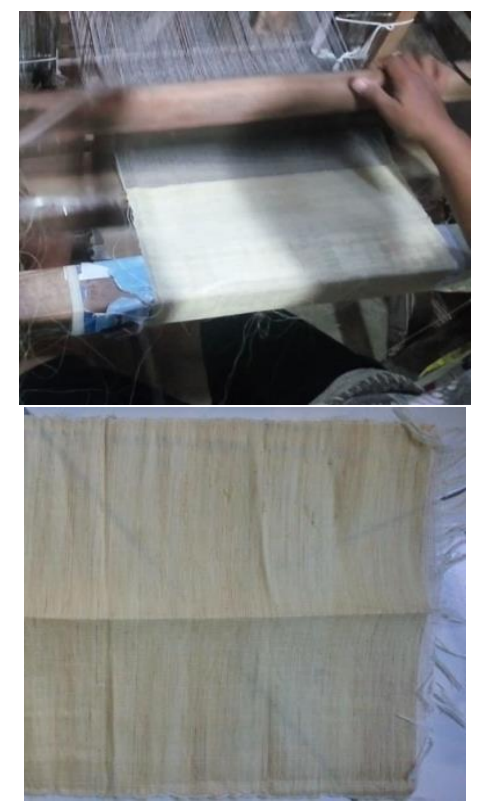

Gambar 10. Proses dan Hasil Penenunan

5. Mempersiapkan alat dan bahan yang akan digunakan untuk proses pencetakan. Alat dan bahan tersebut meliputi : neraca, mistar, pipet, serat rami dan sintetik, resin serta katalis.

6. Mempersiapkan alat Vacuum Infusion dan memastikan rangkaian alat tersebut dapat bekerja dengan sebagaimana mestinya.

7. Mempersiapkan serat rami dan sintetik dengan ukuran $20 \mathrm{~cm}$ x 30 $\mathrm{cm}$ serta menimbang serat tersebut untuk dapat diketahui massa dari serat tersebut.

8. Mempersiapkan cetakan dan meletakkan serat, flow media, inphuply dan bagging film secara berurutan dengan ukuran yang sudah ditentukan.

9. Merangkai sistem masukan dan pengeluaran resin sesuai yang diinginkan dan memastikan tidak terjadi kebocoran pada sistem Vacuum Infusion.

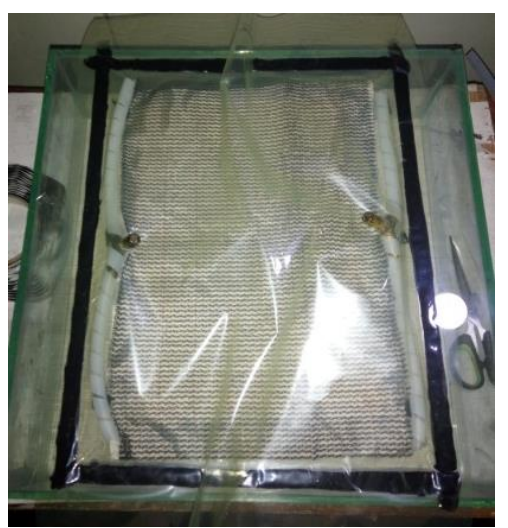

Gambar 11. Proses Pembuatan Panel

10. Mengalirkan resin ke dalam sistem Vacuum Infusion sampai memenuhi cetakan dan memastikan tidak terjadi kebocoran dalam waktu 01.45 menit dengan tekanan 0,4 0,6 Bar.

11. Melakukan proses pembongkaran ketika hasil cetakan sudah kering dalam waktu 12 jam.

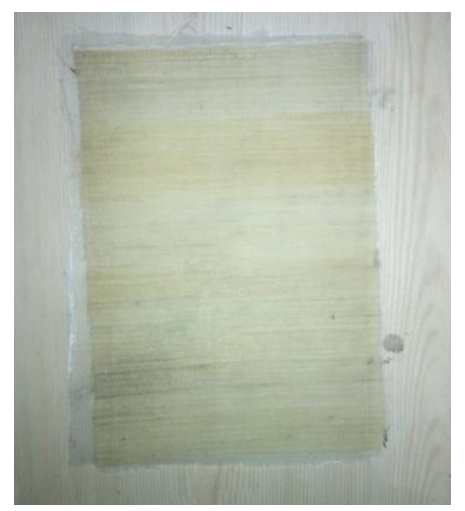

Gambar 12. Hasil Pembuatan Panel 


\section{Proses Pengujian}

Pada pengujian spesimen dilakukan pemotongan panel dengan ukuran standar ASTM D638 untuk pengujian tarik seperti pada gambar 13 di bawah ini :

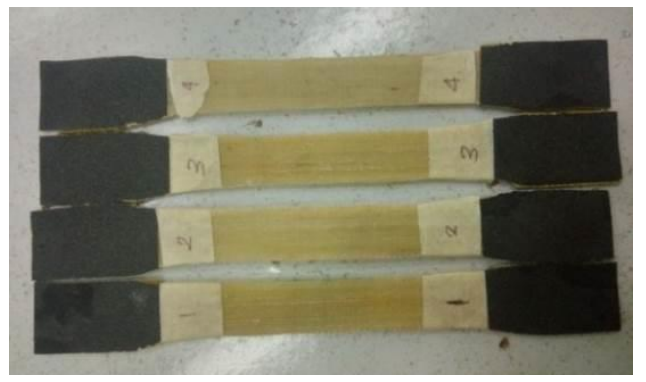

Gambar 13. Spesimen Uji Tarik

Selanjutnya untuk pengujian impact dilakukan pemotongan panel dengan ukuran $80 \mathrm{~mm}$ x $14 \mathrm{~mm}$ sesuai dengan standar ASTM D5492 seperti gambar 14 dibawah ini :

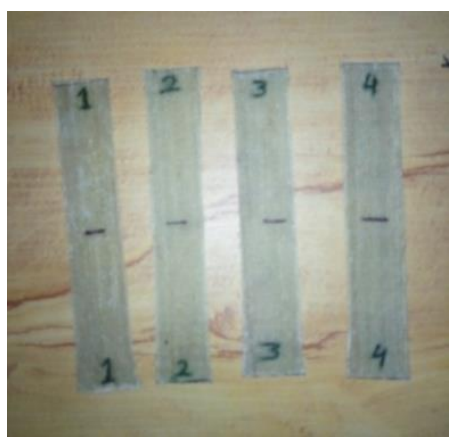

Gambar 14. Spesimen Uji Impact

\section{Proses Pembuatan Mold (cetakan) Cover Knalpot dengan metode vacuum infusion}

Pembuatan pola dengan cara digaris terlebih dahulu dengan di-mal mengunakan cover asli agar saat pemotongan triplek sesuai dengan cover asli knalpot. Jadi pada saat pembuatan sirip-sirip exhaust cover knalpot penempelannya akan lebih mudah, karena sudah ada malnya. Penguatan mold dengan metode hand lay up jadi saat sirip sirip cover sudah jadi dan sudah dilem maka proses selanjutnya adalah penguatan mold dengan menggunakan fiber dan resin agar mold kuat dan tidak bocor cara nya resin dituang ke sirip diratakan dengan kuas lalu serat ditaruh 1 sampai 2 lapis kemudian resin dituang semua ke atas serat dan diratakan sampai resin masuk ke dalam serat tersebut.

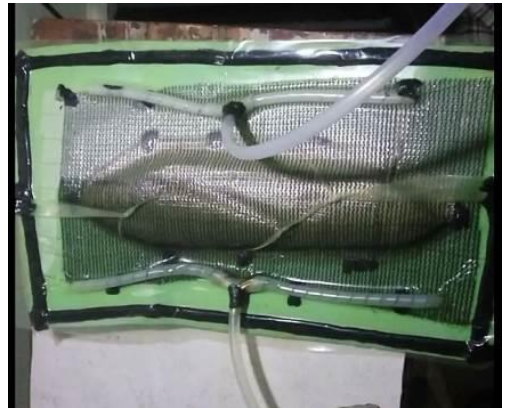

Gambar 15. Metode Vacuum Infusiom

Pada proses finishing ini sangat penting dilakukan karena untuk menentukan cetakan apakah sudah siap dipakai membuat produk atau tidak, maka finishing yang dilakukan adalah meratakan dempul yang bergelombang pada saat pendempulan awal dengan mengamplas dan menambahkan dempul sampai permukaan rata. Kalau sudah rata maka proses selanjutnya finishing menggunakan amplas halus dan sabun untuk menghasilkan permukaan yang halus agar resin mengalir dengan sempurna. Pendempulan juga bertujuan agar tidak ada kebocoran pada permukaan cetakan saat membuat produk dengan metode vacuum infusion.

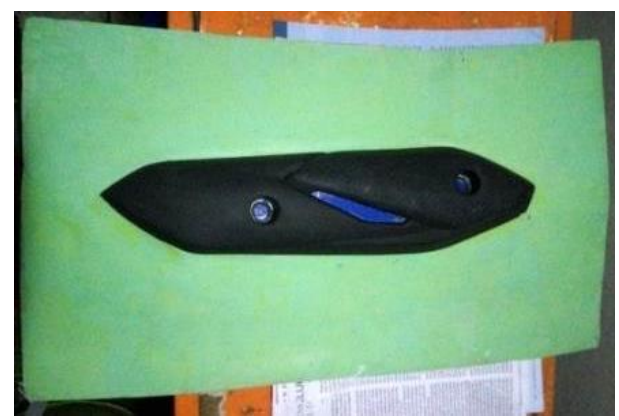

Gambar 16. Finishing Mold

\section{HASIL DAN PEMBAHASAN}

Hasil yang diperoleh dari pembuatan exhaust cover dari bahan komposit hybrid dengan metode vacuum infusion seperti pada gambar 17.

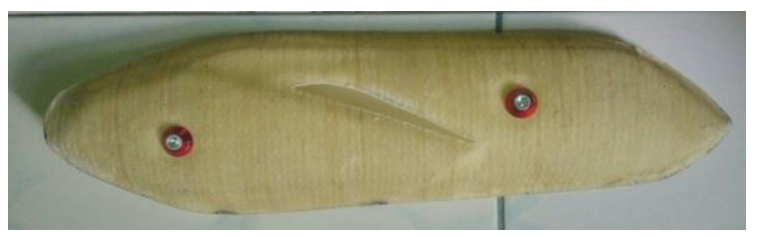

Gambar 17. Hasil Produk Exhaust Cover 
Cover knalpot yang dihasilkan terbuat dari material komposit berpenguat dua lapis serat sintesis (fiber) dan satu lapis serat alam (serat rami) dengan metode vacuum infusion.

Produk komposit berupa cover knalpot menghasilkan material yang ringan dibandingkan dengan cover knalpot pada tipe produk yang serupa. Dimana cover knalpot yang dihasilkan memiliki masa 56,29 gram, hal itu jauh lebih ringan dibanding dengan produk serupa yang memiliki masa 97,42 gram. Selain itu cover knalpot berbahan komposit memiliki sifat ulet dan tipis, sedangkan cover knalpot dengan tipe yang serupa bersifat lebih kaku dan cenderung lebih tebal.

Produk cover knalpot yang dihasilkan terdiri dari material berbahan alam, sehingga ketika produk tersebut tidak terpakai akan dapat terurai. Hal yang berbeda tejadi pada cover knalpot pada umumnya dengan tipe yang serupa dimana pada produk tersebut terbuat dari $100 \%$ plastik, sehingga ketika produk tesebut tidak terpakai akan sulit untuk terurai.

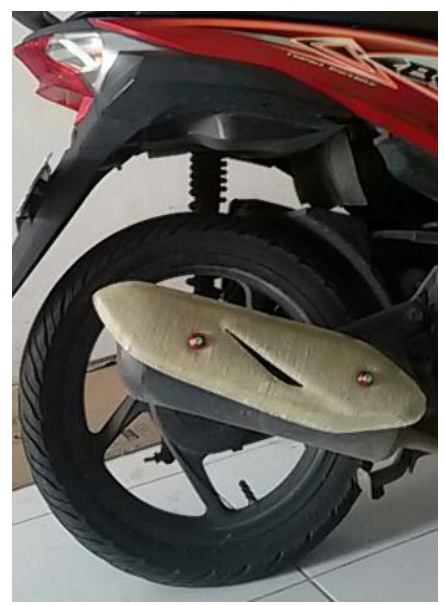

Gambar 18. Pemasangan Cover Knalpot (Exhaust Cover)

\section{Pengujian Tarik}

Pengujian dilakukan dengaan menggunakan alat uji tarik Servo Pulser dengan beban 2 ton yang merujuk pada ASTM D638. Berikut ini adalah data hasil pengujian tarik dari hasil pembuatan material komposit Hybrid serat alam dan sintetis dengan metode terdiri atas dua lapis serat sintetis dan satu lapis serat alam (serat rami) dengan metode Vacuum Infusion.

Tabel 2. Nilai Tegangan pada Pengujian

Tarik

\begin{tabular}{|c|c|c|c|}
\hline $\begin{array}{c}\text { Nama } \\
\text { spesimen }\end{array}$ & $\begin{array}{c}\text { Gaya } \\
(\mathrm{N})\end{array}$ & $\begin{array}{c}\text { Luas } \\
\left(\mathrm{mm}^{2}\right)\end{array}$ & $\begin{array}{c}\text { Teganggan } \\
(\mathrm{MPa})\end{array}$ \\
\hline VI1 & 2665,6 & 18,4 & 144,87 \\
\hline VI2 & 2254 & 17,5644 & 128,33 \\
\hline VI3 & 2900,8 & 17,6653 & 164,21 \\
\hline VI4 & 1999,2 & 16,5997 & 120,44 \\
\hline
\end{tabular}

Dari hasil data tersebut didapat nilai kekuatan tarik tertinggi pada variasi VI 3 dengan tegangan tarik $164,21 \mathrm{MPa}$ serta tegangan tarik terendah pada variasi VI 4 sebesar 120,44 MPa sehingga nilai rata-rata kekuatan tarik tersebut adalah 139,46 MPa. Dengan selisih antara kekuatan tertinggi dan terendah yang tidak terlalu jauh membuktikan bahwa dengan metode vacuum infusion didapat kekuatan material yang seragam.

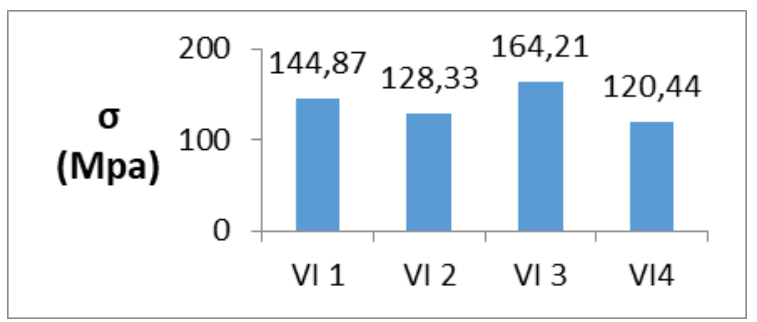

Gambar 19. Diagram Hasil Pengujian Tarik

Hasil data pengujian yang telah diperoleh di atas maka setelah itu akan membandingkan dengan hasil penelitian yang telah dilakukan. Pada variasi pertama menghasilkan penguat terdiri dari 1 alam 2 serat sintetis metode vacuum infusion (VI 1A 2S) dan variasi kedua terdiri dari 1 alam (sisal) 2 sintetik metode press mold serta variasi ketiga terdiri dari 2 serat alam dan 1 serat sintetis dengan cara press mold (PM 2A 1S).

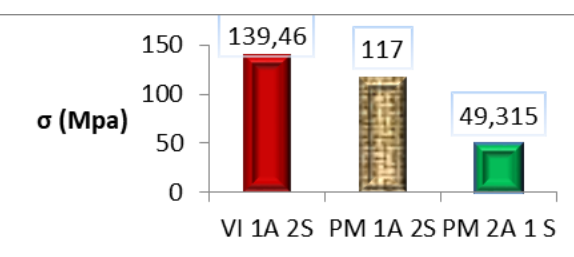

Gambar 20. Diagram Perbandingan Hasil Pengujian Tarik 
Dari hasil grafik tersebut nilai tegangan tarik terendah adalah variasi PM 2A 1S dengan nilai 49,315 Mpa serta nilai tertinggi pada variasi PM 1A 2S dengan nilai $117 \mathrm{Mpa}$. Hal itu disebabkan karena pada proses press mold ketebalan spesimen yang dihasilkan tidak rata dengan demikian spesimen yang mempunyai ketebalan lebih rendah akan mengalami patahan. Selain itu pada proses press mold akan menghasilkan void yang lebih banyak dibanding dengan metode vacuum infusion sehingga daya rekat antara resin dan penguat pada vacuum infusion jauh lebih baik. Dengan demikian nilai tegangan hasil metode vacuum infusion jauh lebih baik dibanding dengan press mold.

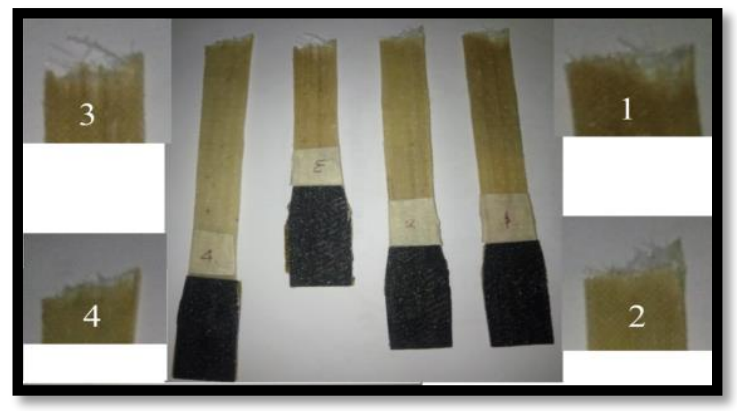

Gambar 21. Penampang Patahan Uji Tarik

Material komposit hybrid terdiri atas dua lapis serat sintetis dan satu lapis serat alam (serat rami) dengan metode Vacuum Infusion pada proses pembuatannya. Hasil dari pengujian impak tercantum pada tabel 3 .

Tabel 3. Hasil Pengujian Impak

\begin{tabular}{|c|c|c|c|c|c|}
\hline $\begin{array}{c}\text { Nama } \\
\text { spesimen }\end{array}$ & $\begin{array}{c}\text { Tebal } \\
(\mathrm{mm})\end{array}$ & $\begin{array}{c}\text { Lebar } \\
(\mathrm{mm})\end{array}$ & $\begin{array}{c}\text { Luas } \\
\left(\mathrm{mm}^{2}\right)\end{array}$ & $\begin{array}{c}\text { Energi } \\
\begin{array}{c}\text { Serap } \\
\left(\mathrm{J} / \mathrm{mm}^{2}\right)\end{array}\end{array}$ & $\begin{array}{c}\text { Energi } \\
\text { impack } \\
\left(\mathrm{J} / \mathrm{mm}^{2}\right)\end{array}$ \\
\hline VI1 & 1,34 & 14,55 & 19,497 & 1,099 & 0,0564 \\
\hline VI2 & 1,09 & 13,78 & 15,0202 & 0,790 & 0,0526 \\
\hline VI3 & 1,19 & 14,69 & 17,4811 & 0,961 & 0,0550 \\
\hline VI4 & 1,22 & 15,22 & 18,5684 & 0,871 & 0,0469 \\
\hline \multicolumn{7}{|c|}{} & $\begin{array}{c}\text { Rata- } \\
\text { rata }\end{array}$ & 0,0527 \\
\hline
\end{tabular}

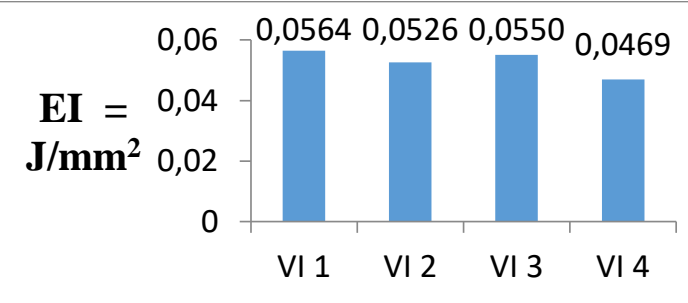

Gambar 22. Diagram Pengujian Impak
Berdasarkan grafik di atas didapatkan nilai energi impak tertinggi pada spesimen VI 1 dengan nilai 0,0564 $\mathrm{J} / \mathrm{mm}^{2}$ dan yang terendah pada pengujian tersebut spesimen VI 4 dengan nilai 0,0469 $\mathrm{J} / \mathrm{mm}^{2}$. Dari grafik tersebut diperoleh nilai ketangguhan komposit yang tidak terlalu besar perbedaannya, hal ini terjadi karena semua spesimen yang digunakan terdiri atas komposisi serta metode pembuatan yang sama.

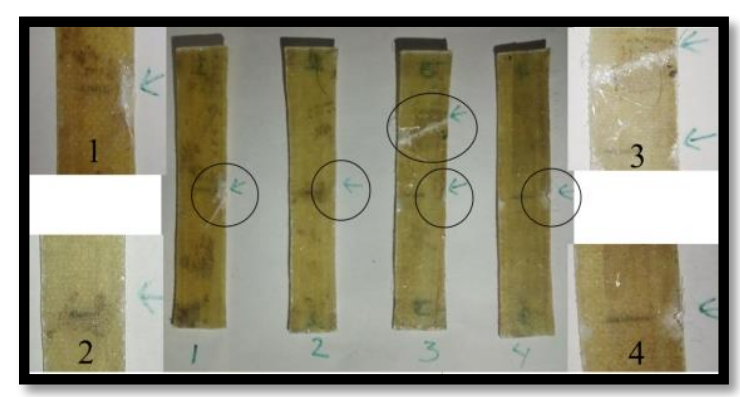

Gambar 23. Hasil Pengujian Impak

Dari hasil pengujian impak yang telah dilakukan didapatkan hasil panel pengujian dalam bentuk gambar 23. Pada hasil tersebut spesimen dengan kode 1, 2 dan 4 tidak mengalami patahan. Hal ini disebabkan karena material komposit memiliki bentuk yang tipis sehingga material tersebut lentur.

Pada spesimen 3 menghasilkan jumlah crack (retak) lebih banyak dibandingkan dengan speimen lainnya. Hal ini terjadi karena pada spesimen 3 mengalami cacat berupa serat alam tidak menyatu sempurna dengan matrik. Energi yang diserap dari pengujian impak akan terpusat pada material yang mengalami kecacatan sehingga retakan yang dihasilkan dari pengujian akan muncul di area tersebut.

\section{KESIMPULAN}

Berdasarkan hasil studi literatur, penelitian, dan analisa serta pembahasan data yang telah dilakukan pada proses pembuatan cover knalpot sepeda motor Honda Beat dengan bahan serat rami metode vacuum infusion, maka dapat disimpulkan sebagai berikut: 
1. Cover knalpot yang dibuat dari serat rami hasil metode vacuum infusion memiliki nilai kekuatan tarik ratarata sebesar $139,5 \mathrm{Mpa}$ dan nilai regangan sebesar $0,1411 \%$ serta nilai modulus elastisitas sebesar $100 \mathrm{Gpa}$.

2. Nilai rata-rata energi serap yang didapat pada pengujian impak cover knalpot sebesar $0,0527 \mathrm{~J} / \mathrm{mm}^{2}$.

3. Cover knalpot yang terbuat dari material komposit memiliki masa yang lebih ringan dan sifat lebih ulet dibanding cover knalpot pada tipe serupa.

\section{REFERENSI}

[1]. Ward, J., Panigrahi, S., Tabil, L. G., Crerar, W. J., \& Powell, T. 2002. Rotational molding of flax fibre reinforced thermoplastics. In An ASAE Meeting Presentation.

[2]. M. Fauzan. 2017. Analisis dansitas dan kekuatan material komposit berpenguat serat glass dari hasil metode Vacuum Infusion, Laporan Tugas Akhir, Jurusan Teknik Mesin D3, Program Vokasi Universitas Muhammadiyah Yogyakarta.

[3]. Lutfi Lunawan. 2017. Kekuatan tarik hybrid lamina serat anyam rami dan glass diperkuat polyester. Pada penelitian tersebut serat rami dialkalisasi menggunakan $\mathrm{NaOH} 5 \%$ selama 2 jam, Laporan Tugas Akhir, Jurusan Teknik Mesin D3, Program Vokasi Universitas Muhammadiyah Yogykarta.

[4]. Yudhanto, F., Sudarisman, S., \& Ridlwan, M. 2016.
Karakterisasi Kekuatan

Tarik Komposit Hybrid Lamina Serat Anyam Sisal dan Gelas Diperkuat Polyester. Jurnal Semesta Teknika, 19(1), 48-54.

[5]. Wardana, P. F. 2013. Pemanfaatan Serbuk Bambu sebagai Alternatif Material Kampas Rem Non-Asbestos Sepeda Motor. Jurnal Nosel, 1(3).

[6]. Hartanto, L. 2009. Study perlakuan alkali dan fraksi volume serat terhadap kekuatan bending, tarik, dan impak komposit berpenguat serat rami bermatrik polyester BQTN 157 (Doctoral dissertation, Universitas Muhammadiyah Surakarta).

[7]. Diharjo K., dan Triyono T. (2000) "Material Teknik". ISBN Buku Pegangan Kuliah Jurusan Teknik Mesin FTUNS: Surakarta. 